Article

\title{
Targeted High Volume Hemofiltration Could Avoid Extracorporeal Membrane Oxygenation in Some Patients with Severe Hantavirus Cardiopulmonary Syndrome
}

René López ${ }^{1,2}$, Rodrigo Pérez-Araos ${ }^{1,3}$, Álvaro Salazar ${ }^{1}$, Mauricio Espinoza $^{1,2}$, Cecilia Vial ${ }^{4}$, Analia Cuiza 4, Pablo A. Vial2, 4, 5, and Jerónimo Graf', ${ }^{2 *}$

1. Departamento de Paciente Crítico, Clínica Alemana de Santiago, Santiago 7650567, Chile; rene.lopezh@gmail.com (R.L.); rperez@alemana.cl (R.P-A.); alvaro.salazarh@gmail.com (Á.S.); mespinoza@alemana.cl (M.E); jeronimograf@yahoo.com (J.G.)

2. Escuela de Medicina. Facultad de Medicina Clínica Alemana Universidad del Desarrollo, Santiago 7710162, Chile; pvial@udd.cl (P.A.V.)

3. Escuela de Kinesiología. Facultad de Medicina Clínica Alemana Universidad del Desarrollo, Santiago 7710162, Chile

4. Programa Hantavirus, Instituto de Ciencias e Innovación en Medicina (ICIM), Facultad de Medicina, Clínica Alemana Universidad del Desarrollo, Santiago 7590943, Chile; mcvialudd@gmail.com (C.V.); lia.cuiza@gmail.com (A.C.)

5. Departamento de Pediatría, Clínica Alemana de Santiago, Santiago 7650567, Chile

* Correspondence: jeronimograf@yahoo.com

\section{Abstract}

Background: Hantavirus cardiopulmonary syndrome (HCPS) has a high lethality. About two-thirds of the severe cases may be rescued by extracorporeal membrane oxygenation (ECMO). However, about half of the patients supported by ECMO suffer major complications. High volume hemofiltration (HVHF) is a depurative extracorporeal support that provides homeostatic balance allowing hemodynamic stabilization in some critically ill patients. Methods: We implemented HVHF prior to ECMO consideration in the last five severe HCPS patients requiring mechanical ventilation and vasoactive drugs admitted to our intensive care unit. Patients were considered HVHF-responders if ECMO was avoided and nonresponders if ECMO support was needed. Results: The first two patients required ECMO, while the last three did not. Patients had a maximum serum lactate of 8.4 [4.3-14] $\mathrm{mMol} / \mathrm{L}$ and a lowest cardiac index of 1.76 [1.45-2.9] L/min/ $/ \mathrm{m}^{2}$. Nonresponders were connected later to HVHF, displayed progressive tachycardia and decreasing stroke volume. The opposite was true for HVHF-responders who also received targeted-HVHF compounded by aggressive hyperoncotic albumin, sodium bicarbonate and calcium supplementation plus ultrafiltration to avoid fluid overload. All patients survived, but one of the ECMO patients suffered a vascular complication. 
Conclusion: HVHF may contribute to support severe HCPS patients avoiding the need for ECMO in some of them. Early connection and targeted-HVHF may increase the chance of success.

Keywords: Hantavirus cardiopulmonary syndrome; Hantavirus pulmonary syndrome; extracorporeal membrane oxygenation; transpulmonary thermodilution; high volume hemofiltration; Andes Hantavirus

\section{Introduction}

Andes Hantavirus (ANDV) is an Orthohantavirus, member of Hantaviridae family, endemic in Chile and Argentina, and its main reservoir is the long-tailed pygmy rice rat (Oligoryzomys longicaudatus) [1]. Humans are infected primarily by the inhalation of aerosolized excreta from infected rodents [2,3]. Additionally, ANDV is the only Hantavirus known to be transmissible between humans [4,5]. The incubation period of ANDV varies from 7 to 39 days [6] followed by a cardiopulmonary phase that evolves from dry cough to respiratory failure due to capillary leak into the pulmonary interstitium, evidenced by chest radiographs showing peribronchial haze and Kerley's B lines that subsequently progresses to alveolar flooding with proteinacieous fluid consistent with non-cardiogenic pulmonary edema (PE) $[7,8]$. Hantavirus cardiopulmonary syndrome (HCPS) also includes circulatory shock compounded by hypovolemia and myocardial depression [9]. Using hemodynamic monitoring with transpulmonary thermodilution (TPTD) in HCPS patients, we recently documented that increased pulmonary vascular permeability (PVP) was associated to hypovolemia and systolic dysfunction [10]. Patients with severe HCPS may ultimately develop refractory hypoxemia and/or circulatory shock that leads to death in up to $35-40 \%$ of patients, making HCPS is one of the deadliest infectious diseases [11-14]. Unfortunately there are no drugs with proven efficacy for HCPS and treatment is based on critical care support including vasoactive drugs, invasive mechanical ventilation (IMV) and extracorporeal support with veno-arterial extracorporeal membrane oxygenation (VA-ECMO) in refractory cases $[12,15]$.

High volume hemofiltration (HVHF) is a form of depurative therapy that has been used as an adjunctive support for refractory septic shock [16,17]. In this therapy blood is drained and returned through a double lumen venous dialysis catheter. Blood passes through a 30,000 Dalton cut-off point hemofilter that filters plasma at a set rate. Filtered fluid is replaced at equivalent or lower rates, depending on set net ultrafiltration (UF) rate, by solutions containing near-normal plasmatic concentrations of electrolytes, glucose and a buffer [18]. As opposed to 
hemodialysis where depuration is attained by diffusion of small molecules, in hemofiltration blood is cleared of small and medium-size molecules by convection [19]. The intensity of depuration is set by the filtration or replacement rate; conventional rates are $25-35 \mathrm{ml} / \mathrm{Kg} / \mathrm{h}$, whereas HVHF uses $50-100 \mathrm{ml} / \mathrm{Kg} / \mathrm{h} \mathrm{[20]}$. The exact mechanism of hemodynamic improvement with HVHF in septic shock is unclear and three main mechanisms have been suggested: 1) removal of ill-defined vasoactive or myocardial depressant factors [21]; 2) immune modulation through plasmatic cytokine peak amputation or their mobilization from tissues and lymphatics [20,22]; and 3) internal homeostasis restoration (acid-base, temperature) devoid of fluid and sodium overload [23]. Despite safety and hemodynamic benefit frequently seen with HVHF in septic shock models $[21,24]$ and clinical case series [16-18,20], randomized clinical trials have not shown consistent improvements in outcome [25]; thus HVHF remains a rescue therapy for refractory septic shock. There are only two reports on the use of depurative therapies in Hantavirus pulmonary syndrome. In 2006 Seitsonen et al. reported the successful use of continuous veno-venous hemodiafiltration in two patients with Puumala virus pulmonary syndrome [26]. Ten years later, Bugedo et al. reported a patient with ADNV severe HCPS successfully supported with HVHF [27].

We present the first clinical case series of patients with ANDV severe HCPS supported with HVHF in addition to vasoactive drugs and IMV, prior to VAECMO consideration. Success or failure of HVHF was stratified according to the subsequent need for VA-ECMO support.

\section{Methods}

\subsection{Study design and patients}

This is an observational retrospective case series. The cohort is part of a prospectively obtained database by the Hantavirus program from the Instituto de Ciencias e Innovación en Medicina, Facultad de Medicina Clínica AlemanaUniversidad del Desarrollo. Our local IRB and ethics committee approved this registry (ID19, September $29^{\text {th }}$ 2011).

For this study, only patients with HCPS admitted to the adult intensive care unit (ICU) at Clínica Alemana de Santiago and supported with IMV and HVHF previous to VA-ECMO consideration were included. The diagnosis of HCPS was confirmed by ANDV specific reverse-transcription polymerase chain reaction (RTqPCR) using an in-house PCR as described in Vial et al. [28]. With this technique we quantified viral genome and determined viremia from the buffycoat. In three 
patients we also performed quantitative enzyme-linked immunosorbent assay (ELISA) detecting ANDV specific immunoglobulin M. Demographic, clinical, laboratory, hemodynamic and pulmonary monitoring data as well as circulatory, ventilatory, hemofiltration and ECMO support variables and relevant outcomes were collected using a standardized case record form. Deidentified data was then entered into a dedicated database.

\subsection{Variables of interest}

Patients were stratified as HVHF-responders if VA-ECMO was avoided and HVHF-nonresponders if VA-ECMO support was needed or death ensued. Hemodynamic, respiratory and laboratory data including variables from TPTD monitoring, oxygenation, blood lactate, vasoactive drug and reanimation fluids requirements were recorded in reference to HVHF onset. Time course of hemodynamic and respiratory variables aligned to HVHF onset and grouped according to HVHF responsiveness is presented. Specific data on HVHF such as hemofilter type, circuit blood flow, replacement fluid rate and net UF volume were recorded.

Transpulmonary thermodilution allows to measure cardiac index $(\mathrm{CI})$, stroke index (SI), volumetric cardiac preload (intrathoracic blood volume index, ITBVi), preload dependency of stroke volume (stroke volume variation, SVV), pulmonary edema (extravascular lung water index, EVLWi) and pulmonary permeability (pulmonary vascular permeability index, PVPI). A detailed explanation of the TPTD technique and all these parameters can be found in our previous report on the topic [10].

\subsection{Hemofiltration procedure}

All hemofiltration procedures were performed with a Diapact ${ }^{\circledR}$ CRRT machine (B.Braun Avitum AG, Melsungen, Germany) using a Diacap ${ }^{\circledR}$ Acute L hemofilter (B.Braun Avitum AG, Melsungen, Germany). These are polysulfone hollow-fiber membranes with a surface area of $2 \mathrm{~m}^{2}$, a sieving coefficient of 0.55 for myoglobin (molecular weight 17,000 Dalton) and a ultrafiltration coefficient of $58 \mathrm{ml} / \mathrm{h} / \mathrm{mmHg}$. Ultrafiltrated fluid was replaced before the filter using Priosol (B. Braun Avitum AG, Melsungen, Germany), a bicarbonate-based solution with the following composition: sodium $140 \mathrm{mMol} / \mathrm{L}$, calcium $1.5 \mathrm{mMol} / \mathrm{L}$, magnesium $0.5 \mathrm{mMol} / \mathrm{L}$, chloride $109 \mathrm{mMol} / \mathrm{L}$, bicarbonate $35 \mathrm{mMol} / \mathrm{L}$, glucose $1 \mathrm{~g} / \mathrm{L}$, and osmolarity 292 $\mathrm{mOsm} / \mathrm{L}$. Potassium was added to maintain the plasmatic concentration between 4 and $5 \mathrm{mMol} / \mathrm{L}$. No anticoagulation was used. 


\section{Results}

We identified five patients with severe HCPS supported with HVHF before considering VA-ECMO support between February and December 2017. These patients are part of the cohort of 11 patients recently reported to describe the TPTD pattern of HCPS [10]. They were all young previously healthy patients, four were male. Individual demographic, virological, laboratory, severity scoring, hemodynamic and respiratory data are shown in tables 1 and 2. Individual time course of hemodynamic and respiratory variables aligned to HVHF onset and grouped according to HVHF responsiveness are shown in figures 1 and 2. All of them had circulatory shock with vasoactive drug requirement and hyperlactatemia (tables 1 and 2). They all received hydrocortisone at stress doses with an initial bolus of $100 \mathrm{mg}$, followed by $50 \mathrm{mg}$ every 6 hours. All of them also had acute respiratory failure with IMV and moderate-to-high positive end expiratory pressure (PEEP) requirement (table 2) under deep sedation with continuous infusions of midazolam and fentanyl as well as neuromuscular blockade with cisatracurium. According to the sequential organ failure assessment (SOFA) score all of them had severe multi-organ failure (table 1). All patients received an intravenous infusion of immune plasma at an ANDV neutralizing antibody dose of $5,000 \mathrm{U} / \mathrm{Kg}$ within 15 hours of admission according to our local protocol [13]. All received HVHF with replacement rates greater than $50 \mathrm{ml} / \mathrm{Kg} / \mathrm{h}$ for at least 6 hours. Individual HVHF settings together with the amount of hyperoncotic albumin, sodium bicarbonate and calcium intravenously added within the first hours of HVHF are shown in table 3. Individual changes in laboratory and TPTD variables induced after 6 to 15 hours of HVHF are shown in table 4. Patients are presented chronologically.

Despite HVHF, the first two patients continued to deteriorate their circulatory failure as attested by declining SI, CI, ITBVi and rising blood lactate levels while oxygenation worsened and they ultimately required VA-ECMO support (figure 1 and 2, table 4). The second patient had an ECMO-related vascular complication; a large superinfected hematoma of the groin that required vascular and reconstructive surgery with a lengthy hospital stay and a protracted recovery (table 1).

The third patient exhibited a dual behavior after HVHF initiation; initially, SI continued to decrease and CI was maintained at the expense of progressive tachycardia and increasing catecholamine doses, but lactate levels continued to rise (figure 1, table 4). After 9 hours of ineffective standard HVHF, a trial of targeted HVHF was started. This modified approach consisted of aggressive fluid 
resuscitation with hyperconcotic albumin $(20 \%, 400 \mathrm{ml})$ and sodium bicarbonate $(1.4 \%, 1500 \mathrm{ml}$ and $5.6 \%, 500 \mathrm{ml})$ in addition to calcium supplementation while aggressive UF was added to HVHF (table 3). The target was to rapidly correct hypoalbuminemia and metabolic acidosis while keeping ionic calcemia in the upper normal range and avoiding fluid overload (tables 3 and 4). Shortly after this strategy was started, SI increased more than three times, CI rose more than two times and a prominent lactate washout curve followed (figure 1, table 4). Oxygenation impairment, lung edema and increased pulmonary vascular permeability remained stable through the course of this dual hemodynamic course (figure 2).

The fourth patient also received supplemental hyperoncotic albumin, sodium bicarbonate and calcium while aggressive UF was added to HVHF (table 3). He had a rapid hemodynamic improvement increasing SI with relatively small increases in ITBVi, reducing tachycardia and lactate levels (figure 1 and table 4). This patient had the least pulmonary involvement of this series. He improved oxygenation and slightly decreased EVLWi and PVPI throughout the course of HVHF (figure 2).

The fifth patient was intubated 24 hours before referral to our center and was transferred as a VA-ECMO candidate. Upon arrival to our center he received large intravenous fluid boluses of hyperconcotic albumin $(20 \%, 400 \mathrm{ml})$, immune plasma $(500 \mathrm{ml})$ and hypertonic sodium bicarbonate $(5.6 \%, 750 \mathrm{ml})$ together with calcium supplementation while HVHF was started with a net UF rate of $800 \mathrm{ml} /$ hour (table 3). Stroke index, CI and ITBVi rapidly increased and then stabilized while lactate cleared (figure 1, table 4) at the cost of a transient increase in EVLWi and oxigenation impairment (figure 2). These last three patients did not require VAECMO support and were free of vascular complications. The last two had a fast uneventful recovery with only four days of IMV and less than a week of ICU stay. All the patients were discharged home, returned to their previous activities and are still alive. The only sequela was intermittent claudication of one leg in the second patient.

\section{Discussion}

To our best knowledge this is the largest report on HVHF use in severe HCPS. The main observation was the ability to successfully support severe circulatory and respiratory failure, avoiding VA-ECMO connection, in 3 of 5 severe HCPS patients in whom preemptive HVHF was used. Four of them had a CI $<2.0 \mathrm{~L} / \mathrm{min} / \mathrm{m}^{2}$ and four had a blood lactate level $>4 \mathrm{mMol} / \mathrm{L}$; both features being part of the ECMO connection criteria for severe HCPS established by Crowley et al [15]. 
Responsiveness to a HVHF pulse in septic shock has been traditionally assessed by catecholamine requirement, cardiac output and lactate clearance [16-18]. We used VA-ECMO need as comprehensive criteria of HVHF responsiveness in these patients.

The key question left is why did some patients responded to HVHF improving hemodynamics while others continued to deteriorate, ultimately requiring VAECMO support to avoid demise. Two simple answers may be given; either nonresponders were sicker, or there were differences in the HVHF procedure provided to responders and non-responders. We will examine the data supporting these alternative explanations.

Nonresponders could be considered more severely ill on the basis of the greatest viremia (patient 1), lower platelet counts (table 1), higher temperature (table 4), lower SI (tables 2 and 4, figure 1), the greatest severity of respiratory failure (patient 1; table 2 and figure 2) and the greatest pulmonary edema in the cohort (patient 2; table 2 and figure 2). It could be argued against this explanation that severity scores, peak PVPI, hemoconcentration and lactate levels were similar between responders and non-responders. On the other hand, there were several differences in the way HVHF was given to responders and nonresponders; firstly HVHF was started earlier in responders (table 3). Secondly, in contrast to nonresponders, responders received a targeted HVHF compounded by aggressive fluid resuscitation based on hyperoncotic albumin and sodium bicarbonate while calcium was supplemented and UF was added to HVHF with the aim of normalizing plasmatic albumin, bicarbonate and ionic calcium while avoiding fluid overload (tables 3 and 4). Patient 3 provides a good comparison of the standard and targeted HVHF approaches. Although early connected to standard $H V H F$, this patient initially seemed to follow the path of hemodynamic deterioration of patients 1 and 2, but when switched to targeted HVHF, SI rose, HR dropped and lactate washed out. We saw the same behavior on patients 4 and 5 . The whole series seems to suggest a learning curve in terms of both progressively earlier connection and active HVHF optimization to swiftly restore homeostasis.

Trying to understand the observed response to HVHF we will first review the effects and invoked mechanisms of standard HVHF and, then, we will try to explain why a targeted approach could improve those results. The first report of hemofiltration in a canine septic model showed a reversal of myocardial depression ascribed to the removal of a filterable cardiodepressant factor [21]. The first report of HVHF in an endotoxic shock model showed an improvement in myocardial performance attributed to removal of vasoactive mediators that 
produced myocardial depression [24]. In a subsequent pneumonia model myocardial depression was reversed by early but not by delayed hemofiltration suggesting that timing of the intervention could be of importance [29]. In the first large case series, twenty patients with refractory hypodynamic septic shock were subjected to HVHF; nearly half of them showed reversal of myocardial depression and most of those survived [16]. Again, and similar to our HCPS series, an earlier onset of HVHF was associated to a greater likelihood of positive response [16]. Since then, a number of relatively small studies have suggested a favorable hemodynamic effect of HVHF in septic shock patients mostly in terms of reductions in doses of catecholamines [17,30,31], but also in terms of improved oxygenation [18,32]. The dominant explanation for these favorable effects has been the convective or adsorptive removal of unselected pro and anti-inflammatory mediators by HVHF that could contribute to control the cytokine storm associated to septic shock $[20,22]$. However, the reductions in cytokine plasma levels achieved by HVHF have been marginal in most cases and other explanations, such as their removal from tissues have been therefore invoked [22].

On the other hand, some have suggested that the mechanism of hemodynamic improvement by HVHF is a homeostatic effect based on ability to control body temperature and internal body fluid composition [23]. Along these lines, targeted HVHF could have boosted the benefits of standard HVHF through the following potential mechanisms:

1. Correction of metabolic acidosis and calcium supplementation. Metabolic acidosis is known to depress myocardial function [33] and to reduce catecholamine responsiveness in myocardiocytes and vascular smooth muscle cells [34]. It also produces acidemic pulmonary vasoconstriction [33] that may contribute to acute cor pulmonale in the context of acute respiratory distress syndrome [35]. During circulatory failure a vicious cycle may be established where tissue hypoperfusion leads to metabolic acidosis and metabolic acidosis further impairs cardiovascular response. To stop this vicious cycle adequate resuscitation could include fluids rich in bicarbonate. This debatable strategy has not consistently translated into positive results likely due to the generation of large amounts of $\mathrm{CO}_{2}$ that need to be ventilated, a decrease in ionic calcium concentrations [34] and, in the context of leaky vessels, interstitial space expansion hampering gas exchange in the lung and eventually myocardial function itself [10]. HVHF offers then the possibility of rapidly exchanging extracellular fluid (ECF) composition without inducing fluid overload. Given the replacement fluid bicarbonate concentration of $35 \mathrm{mMol} / \mathrm{L}, \mathrm{HVHF}$ tends by itself to correct metabolic acidosis. When this effect is insufficient or too slow, sodium bicarbonate can 
be given externally while equivalent volumes of net UF are added to keep fluid balance even or negative. At the same time minute ventilation can be transiently increased to clear the extra $\mathrm{CO}_{2}$ produced and calcium chloride can be supplemented to counter the drop in ionic calcium. Such a strategy raised extracellular and intracellular $\mathrm{pH}$ along with improved cardiac contractility and vascular responsiveness to catecholamines in a rat model of severe lactic acidosis [36]. This was done in all our patients, but was more visibly purposeful during targeted $H V H F$.

2. Hyperoncotic albumin fluid resucitation. It is well known that during extreme hypovolemia cardiac performance assessed by load dependent variables such as ejection fraction may be reduced [37]. Acute intravascular expansion may even improve load independent ventricular contractility variables [38]. The risk of fluid resuscitation in the context of leaky capillaries, such as in HCPS, is to exacerbate ECF expansion, lung edema and respiratory failure. One answer to this classical critical care conundrum is the use of colloids as resuscitation fluids. Artificial colloids have been abandoned due to side effects, and despite lack of robust evidence of benefit, albumin is the only colloid still in use in this context [39]. In septic patients a bolus of $200 \mathrm{ml}$ of $20 \%$ albumin expands intravascular volume by $430 \mathrm{ml}$ at 30 minutes [40]. There are a number of additional benefits of albumin as a resuscitation fluid besides preload augmentation. For example, it has shown positive effects on myocardial contractility, in models of endotoxemia [41] or cirrhotic myocardial depression [42]. The largest trial on the use of $20 \%$ albumin, the ALBIOS trial, showed that in patients with severe sepsis a strategy aimed to maintain serum albumin concentrations greater than $3 \mathrm{~g} / \mathrm{dL}$ was associated to higher mean arterial pressure and lower net fluid balance; moreover, when the analysis was restricted to the 1,121 patients with septic shock, 20\% albumin showed a 90 days survival benefit over crystalloids [43]. This has led to the concept of the so called "small volume resuscitation" with $20 \%$ albumin [44]. In healthy volunteers a $20 \%$ albumin bolus produced a larger increase in SI than a crystalloid bolus five times larger, but without inducing pulmonary edema and increasing lung diffusion capacity at the same time, suggesting balanced salutary hemodynamic and pulmonary effects [45]. In our severe HCPS patients we used large boluses of $20 \%$ albumin, particularly during targeted HVHF. This may have contributed to the hemodynamic stabilization that averted VA-ECMO connection in HVHF responders. The fifth patient provides a good example; $400 \mathrm{ml}$ of $20 \%$ albumin were given, ITBVi increased, SI increased, HR dropped and lactate washed out (figure 1 and table 4 ). 
3. Fluid overload management. During targeted HVHF not only isovolemic HVHF took place, but large net UF amounting nearly between 2.5 and $5 \mathrm{~L}$ was added to give room for sodium bicarbonate, hyperoncotic albumin and immune plasma while sparing fluid accumulation. Without hemofiltration and UF, corrections of imbalances in ECF composition as the ones achieved are usually accompanied by fluid overload. Fluid overload has been independently associated to unfavorable outcomes in ICU patients [46] and should be avoided in HCPS [47]. As it was seen respiratory failure that could be contained using a high PEEP level (figure 2 and table 4). Ultrafiltration allows to dynamically balance cardiac preload optimization and containment of pulmonary flooding as achieved in patients 3 and 4 who slightly increased their ITBVi without increasing EVLWi (figures 1 and 2, table 4). Targeted HVHF could provide a mechanism to achieve homeostasis while keeping a neutral or negative fluid balance, withholding hemodynamic impairment until endothelial tight junctions are restored.

4. Temperature control. Fever increases oxygen consumption and $\mathrm{CO}_{2}$ production [48]. Convective depurative therapies such as HVHF produce heat loss $[23,49]$ that could reduce metabolic oxygen consumption and $\mathrm{CO}_{2}$ production [50]. In the context of circulatory failure where oxygen delivery to the tissues is insufficient to sustain tissue demands, a reduction in the metabolic rate through temperature control could help to avoid tissue oxygen debt and restore homeostasis [48]. In fact, mild hypothermia improved stroke volume, mean arterial pressure, mixed venous oxygen saturation and survival in a swine cardiogenic shock model [51]. In patients with cardiogenic shock mild hypothermia has been shown to reduce heart rate and catecholamine requirements while increasing ejection fraction [52]. Additionally, a randomized trial of external cooling in patients with septic shock showed decreased requirement of vasopressors and short term mortality in the intervention arm [53]. Temperature control could be therefore another potential mechanism of benefit of HVHF. Even though in our series temperature reduction was more prominent in HVHF nonresponders, absolute temperature reached was lower in HVHF responders (table 4 ).

Severe HCPS remains an infectious disease with a high lethality. Hemodynamic monitoring with TPTD allows identifying a characteristic pattern and may help to decide the need for VA-ECMO support [10]. Moreover, VA-ECMO has allowed decreasing mortality from $100 \%$ to $33 \%$ in the most severe HCPS cases [13]. Unfortunately, vascular complications mainly related to the arterial vascular access as well as bleeding, related to the need for systemic anticoagulation in the context 
of thrombocytopenia, make VA-ECMO a suboptimal life support technique. In fact, one of our two ECMO patients had severe vascular morbidity. This highlights the need to explore alternative support measures for severe HCPS. High volume hemofiltration, perhaps with a targeted approach as the outlined, could fill this gap.

Though provoking, the current report has weaknesses related to its observational nature and small size precluding statistical analyses. However, only one case report of severe HCPS due to ANDV successfully supported with HVHF has been previously been reported.

In conclusion, considering the lack of specific therapy for HCPS, the significant morbidity attributable to VA-ECMO and the ease of HVHF in the ICU setting, our report provides relevant data to consider an early targeted HVHF trial in severe HCPS. Given the uncertainty of the response to HVHF and the mortality of severe HCPS, such a trial should only be performed in centers with ECMO capability. The observational nature and small size of the cohort preclude of stronger inferences.

Author Contributions: Conceptualization, J.G., R.L., M.E. and P.A.V.; methodology, J.G., R.L., R.P.-A. and C.V.; study design, J.G., R.L., R.P-A., M.E. and P.A.V.; data management,., R.P-A., Á.S., C.V., A.C., R.L. and J.G.; formal analysis, J.G., R.L., R.P-A., and M.E.; writing-original draft preparation, J.G., R.L., R.P-A., Á.S., M.E., C.V., A.C. and P.A.V.; funding acquisition, P.A.V.

Funding: Fondo Nacional de Investigación en Salud (FONIS) (grant number SAO7120045); Fondo Nacional de Ciencia y Tecnología (Fondecyt) (grant number 1161447 and 1201240).

Acknowledgments: The authors are very grateful to Dr. Vinko Tomicic for pioneering and mentoring the use of applied physiology as one of the basis of sound critical care provision in our intensive care unit. The authors are also very grateful to the devoted and silent work of renal replacement therapy team of nurses in our unit.

Conflicts of Interest: The authors declare no conflict of interest.

\section{References}

1. Medina, R.A.; Torres-Perez, F.; Galeno, H.; Navarrete, M.; Vial, P.A.; Palma, R.E.; Ferres, M.; Cook, J.A.; Hjelle, B. Ecology, Genetic Diversity, and Phylogeographic Structure of Andes Virus in Humans and Rodents in Chile. J. Vir. 2009, 83, 2446-2459. doi: 10.1128/JVI.01057-08 
2. Hart, C.A.; Bennett, M. Hantavirus infections: Epidemiology and pathogenesis. Microbes. Infect. 1999, 1, 1229-1237. doi: 10.1016/s1286-4579(99)00238-5.

3. Sotomayor, V.; Aguilera, X. Epidemiología de la infección humana por Hantavirus en Chile. Rev. Chil. Infectología. 2000, 17, 2320-2327. doi: 10.4067/S0716-10182000000300006

4. Padula, P.J.; Edelstein, A.; Miguel, S.D.; López, N.M.; Rossi, C.M.; Rabinovich, R.D. Hantavirus pulmonary syndrome outbreak in Argentina: Molecular evidence for person-to-person transmission of Andes virus. Virology 1998, 241, 323-330. doi: 10.1006/viro.1997.8976

5. Martinez-Valdebenito, C.; Calvo, M.; Vial, C.; Mansilla, R.; Marco, C.; Palma, R.E.; Vial, P.A.; Valdivieso, F.; Mertz, G.; Ferrés, M. Person-to-person household and nosocomial transmission of Andes Hantavirus, Southern Chile, 2011. Emerg. Infect. Dis. 2014, 20, 1629-1636. doi: 10.3201/eid2010.140353

6. Vial, P.A.; Valdivieso, F.; Mertz, G.; Castillo, C.; Belmar, E.; Delgado, I.; Tapia, M.; Ferrés, M. Incubation period of hantavirus cardiopulmonary syndrome. Emerg. Infect. Dis. 2006, 12, 1271-1273. doi: 10.3201/eid1208.051127

7. Manigold, T.; Vial, P. Human Hantavirus infections: Epidemiology, clinical features, pathogenesis and immunology. Swiss Med. Wkly. 2014, 144, 1-10. doi: 10.4414/smw.2014.13937.

8. Mertz, G.J.; Hjelle, B.; Crowley, M.; Iwamoto, G.; Tomicic, V.; Vial, P.A. Diagnosis and treatment of new world Hantavirus infections. Curr. Opin. Infect. Dis. 2006, 19, 437-442. doi: 10.1097/01.qco.0000244048.38758.1f

9. Hallin, G.W.; Simpson, S.Q.; Crowell, R.E.; James, D.S.; Koster, F.T.; Mertz, G.J.; Levy, H. Cardiopulmonary manifestations of hantavirus pulmonary syndrome. Crit. Care. Med. 1996, 24, 252258. doi: 10.1097/00003246-199602000-00012.

10. López, R.; Pérez-Araos R.; Salazar Á.; Ulloa A.L.; Vial C.; Vial P.A.; Graf J. Hemodynamic and Pulmonary Permeability Characterization of Hantavirus Cardiopulmonary Syndrome by Transpulmonary Thermodilution. Viruses 2019, 11, 900. doi: 10.3390/v11100900.

11. Duchin, J.; Koster, F.; Peters, C.; Simpson, G.; Tempest, B.; Zaki, S.R.; Ksiazek, T.G.; Rollin, P.E.; Nichol, S.; Umland, E.T.; et al. Hantavirus Pulmonary Syndrome: A Clinical Description of 17 Patients with newly recognize disease. N. Engl. J. Med. 1994, 330, 949-955. doi: 10.1056/NEJM199404073301401.

12. Wernly, J.A.; Dietl, C.A.; Tabe, C.E.; Pett, S.B.; Crandall, C.; Milligan, K.; Crowley, M.R. Extracorporeal membrane oxygenation support improves survival of patients with Hantavirus cardiopulmonary syndrome refractory to medical treatment. Eur. J. Cardiothorac. Surg. 2011, 40, 13341340. doi: 10.1016/j.ejcts.2011.01.089.

13. Vial, P.A.; Valdivieso, F.; Calvo, M.; Rioseco, M.L.; Riquelme, R.; Araneda, A.; Tomicic, V.; Graf, J.; Paredes, L.; Florenzano, M.; et al. A non-randomized multicentre trial of human immune plasma for treatment of hantavirus cardiopulmonary syndrome by ANDV. Antivir. Ther. 2014, 20, 377-386. doi: 10.3851/IMP2875.

14. Vial, P.A.; Valdivieso, F.; Ferres, M.; Riquelme, R.; Rioseco, M.L.; Calvo, M.; Castillo, C.; Díaz, R.; Scholz, L.; Cuiza, A.; et al. High-dose intravenous methylprednisolone for hantavirus cardiopulmonary syndrome in Chile: A double-blind, randomized controlled clinical trial. Clin. Infect. Dis. 2013, 57, 943-951. doi: 10.1093/cid/cit394.

15. Crowley, M.R.; Katz, R.W.; Kessler, R.; Simpson, S.Q.; Levy, H.; Hallin, G.W.; Cappon, J.; Krahling, J.B.; Wernly, J. Successful treatment of adults with severe Hantavirus pulmonary syndrome with extracorporeal membrane oxygenation. Crit. Care Med. 1998, 26, 409-414. doi: 10.1097/00003246$199802000-00047$.

16. Honoré, P.M.; Jamez, J.; Wauthier, M.; Lee, P.A.; Dugernier, T.; Pirenne, B.; Hanique, G.; Matson, J.R. Prospective evaluation of short-term, high-volume isovolemic hemofiltration on the hemodynamic course and outcome in patients with intractable circulatory failure resulting from septic shock. Crit. Care Med. 2000, 11, 3581-3587. doi: 10.1097/00003246-200011000-00001

17. Cornejo, R.; Downey, P.; Castro, R.; Romero, C.; Regueira, T.; Vega, J.; Castillo, L.; Andresen, M.; Dougnac, A.; Bugedo, G.; Hernandez, G. High-volume hemofiltration as salvage therapy in severe hyperdynamic septic shock. Intensive Care Med. 2006, 32, 713-722. doi: 10.1007/s00134-006-0118-5 
18. Tapia, P.; Chinchón, E.; Morales, D.; Stehberg, J.; Simon, F. Effectiveness of short-term 6-hour highvolume hemofiltration during refractory severe septic shock. J. Trauma Acute Care Surg. 2012, 72, 1228-1237. doi: 10.1097/TA.0b013e318248bc6c.

19. Davenport, A. Moving beyond small solute clearance: What evidence is there for more permeable dialyzers and haemodiafiltration? Hemodial. Int. 2018, 22, S24-S28. doi: 10.1111/hdi.12700.

20. Ratanarat, R.; Brendolan, A.; Ricci, Z.; Salvatori, G.; Nalesso, F.; de Cal, M.; Cazzavillan, S.; Petras, D.; Bonello, M.; Bordoni, V.; et al. Pulse high-volume hemofiltration in critically ill patients: a new approach for patients with septic shock. Semin. Dial. 2006, 19, 69-74. doi: 10.1111/j.1525139X.2006.00121.

21. Gomez, A.; Wang, R.; Unruh, H.; Light, R.B.; Bose, D.; Chau, T.; Correa, E.; Mink, S. Hemofiltration reverses left ventricular dysfunction during sepsis in dogs. Anesthesiology 1990, 73, 671-685. doi: 10.1097/00000542-199010000-00013.

22. Honoré, P.M.; Joannes-Boyau, O.; Boer, W. High-flow Hemofiltration as an Adjunctive Therapy in Sepsis. In Yearbook of Intensive Care and Emergency Medicine; Vincent, J.L., Eds.; Springer: Berlin, Heidelberg, Germany, 2009; pp. 119-128.

23. Oudemans-van Straaten, H.M.; Elbers, P.W. How to explain and exploit the beneficial effects of highvolume hemofiltration on hemodynamics and strong ion gap. Intensive Care Med. 2013, 39, 1140-1142. doi: 10.1007/s00134-013-2820-4.

24. Grootendorst, A.F.; van Bommel, E.F.; van der Hoven, B.; van Leengoed, L.A.; van Osta, A.L. High volume hemofiltration improves right ventricular function in endotoxin-induced shock in the pig. Intensive Care Med. 1992, 18, 235-240. doi: 10.1007/BF01709839.

25. Joannes-Boyau, O.; Honoré, P.M.; Perez, P.; Bagshaw, S.M.; Grand, H.; Canivet, J.L.; Dewitte, A.; Flamens, C.; Pujol, W.; Grandoulier, A.S.; et al. High-volume versus standard-volume haemofiltration for septic shock patients with acute kidney injury (IVOIRE study): a multicentre randomized controlled trial. Intensive Care Med. 2013, 39, 1535-1546. doi: 10.1007/s00134-013-2967-z.

26. Seitsonen, E.; Hynninen, M.; Kolho, E.; Kallio-Kokko, H.; Pettilä, V. Corticosteroids combined with continuous veno-venous hemodiafiltration for treatment of hantavirus pulmonary syndrome caused by Puumala virus infection. Eur. J. Clin. Microbiol. Infect. Dis. 2006, 25, 261-266. doi: 10.1007/s10096006-0117-z.

27. Bugedo, G.; Florez, J.; Ferres, M.; Roessler, E.; Bruhn, A. Hantavirus cardiopulmonary syndrome successfully treated with high-volume hemofiltration. Rev. Bras. Ter. Intensiva. 2016, 28, 190-194. doi: 10.5935/0103-507X.20160032.

28. Vial, C., Martinez-Valdebenito, C., Rios, S., Martinez, J., Vial, P. A., Ferres, M., Rivera, J.C., Perez, R., Valdivieso, F. Molecular method for the detection of Andes Hantavirus infection: validation for clinical diagnostics. Diagn. Micr. Infec. Dis. 2016, 84, 36-39. doi: 10.1016/j.diagmicrobio.2015.07.019

29. Mink, S.N.; Li, X.; Bose, D.; Gu, M.; Liu, G.; Jacobs, H.; Light, R.B. Early but not delayed continuous arteriovenous hemofiltration improves cardiovascular function in sepsis in dogs. Intensive Care Med. 1999, 25, 733-743. doi: 10.1007/s001340050938.

30. Cole, L.; Bellomo, R.; Journois, D.; Davenport, P.; Baldwin, I.; Tipping, P. High-volume haemofiltration in human septic shock. Intensive Care Med. 2001, 27, 978-986. doi: 10.1007/s001340100963.

31. Joannes-Boyau, O.; Rapaport, S.; Bazin, R.; Fleureau, C.; Janvier, G. Impact of high volume hemofiltration on hemodynamic disturbance and outcome during septic shock. ASAIO J. 2004, 50, 102-109. doi: 10.1097/01.mat.0000104846.27116.ea.

32. Piccinni, P.; Dan, M.; Barbacini, S.; Carraro, R.; Lieta, E.; Marafon, S.; Zamperetti, N.; Brendolan, A.; D'Intini, V.; Tetta, C.; et al. Early isovolaemic haemofiltration in oliguric patients with septic shock. Intensive Care Med. 2006, 32, 80-86. doi: 10.1007/s00134-005-2815-x.

33. Teplinsky, K.; O'Toole, M.; Olman, M.; Walley, K.R.; Wood, L.D. Effect of lactic acidosis on canine hemodynamics and left ventricular function. Am. J. Physiol. 1990, 258, H1193-H1199. doi: 10.1152/ajpheart.1990.258.4.H1193. 
34. Kimmoun, A.; Novy, E.; Auchet, T.; Ducrocq, N.; Levy, B. Hemodynamic consequences of severe lactic acidosis in shock states: from bench to bedside. Crit. Care. 2015, 19, 175. doi: 10.1186/s13054-0150896-7.

35. Guérin, C.; Matthay, M.A. Acute cor pulmonale and the acute respiratory distress syndrome. Intensive Care Med. 2016, 42, 934-936. doi: 10.1007/s00134-015-4197-z.

36. Kimmoun, A.; Ducrocq, N.; Sennoun, N.; Issa, K.; Strub, C.; Escanyé, J.M.; Leclerc, S.; Levy, B. Efficient extra- and intracellular alkalinization improves cardiovascular functions in severe lactic acidosis induced by hemorrhagic shock. Anesthesiology. 2014, 120, 926-934. doi: 10.1097/ALN.0000000000000077.

37. Robotham, J.L.; Takata, M.; Berman, M.; Harasawa, Y. Ejection fraction revisited. Anesthesiology. 1991, 74, 172-183. doi: 10.1097/00000542-199101000-00026.

38. Lew, W.Y. Time-dependent increase in left ventricular contractility following acute volume loading in the dog. Circ. Res. 1988, 63, 635-647. doi: 10.1161/01.res.63.3.635.

39. Zazzeron, L.; Gattinoni, L.; Caironi, P. Role of albumin, starches and gelatins versus crystalloids in volume resuscitation of critically ill patients. Curr. Opin. Crit. Care. 2016, 22, 428-436. doi: 10.1097/MCC.0000000000000341.

40. Margarson, M.P.; Soni, N.C. Changes in serum albumin concentration and volume expanding effects following a bolus of albumin $20 \%$ in septic patients. Br. J. Anaesth. 2004, 92, 821-826. doi: 10.1093/bja/aeh111. Epub 2004 Apr 2.

41. Walley, K.R.; McDonald, T.E.; Wang, Y.; Dai, S.; Russell, J.A. Albumin resuscitation increases cardiomyocyte contractility and decreases nitric oxide synthase II expression in rat endotoxemia. Crit. Care Med. 2003, 31, 187-194. doi: 10.1097/00003246-200301000-00029.

42. Bortoluzzi, A.; Ceolotto, G.; Gola, E.; Sticca, A.; Bova, S.; Morando, F.; Piano, S.; Fasolato, S.; Rosi, S.; Gatta, A.; Angeli, P. Positive cardiac inotropic effect of albumin infusion in rodents with cirrhosis and ascites: molecular mechanisms. Hepatology. 2013, 57, 266-276. doi: 10.1002/hep.26021.

43. Caironi, P.; Tognoni, G.; Masson, S.; Fumagalli, R.; Pesenti, A.; Romero, M.; Fanizza, C.; Caspani, L.; Faenza, S.; Grasselli, G.; et al.; ALBIOS Study Investigators. Albumin replacement in patients with severe sepsis or septic shock. N. Engl. J. Med. 2014, 370, 1412-1421. doi: 10.1056/NEJMoa1305727.

44. Mårtensson, J.; Bihari, S.; Bannard-Smith, J.; Glassford, N.J.; Lloyd-Donald, P.; Cioccari, L.; Luethi, N.; Tanaka, A.; Crisman, M.; Rey de Castro, N.; et al. Small volume resuscitation with $20 \%$ albumin in intensive care: physiological effects. The SWIPE randomised clinical trial. Intensive Care Med. 2018, 44, 1797-1806. doi: 10.1007/s00134-018-5253-2.

45. Bihari, S.; Wiersema, U.F.; Perry, R.; Schembri, D.; Bouchier, T.; Dixon, D.; Wong, T.; Bersten, AD. Efficacy and safety of $20 \%$ albumin fluid loading in healthy subjects: a comparison of four resuscitation fluids. J. Appl. Physiol. 2019, 126, 1646-1660. doi: 10.1152/japplphysiol.01058.2018.

46. O'Connor, M.E.; Prowle, J.R. Fluid Overload. Crit. Care Clin. 2015, 31, 803-821. doi: 10.1016/j.ccc.2015.06.013.

47. Campos, G.M.; Borges, A.A.; Badra, S.J.; Figueiredo, G.G.; Souza, R.L.; Moreli, M.L.; Figueiredo, L.T. Pulmonary and cardiovascular syndrome due to hantavirus: clinical aspects of an emerging disease in southeastern Brazil. Rev. Soc. Bras. Med. Trop. 2009, 42, 282-289. doi: 10.1590/s0037-86822009000300009.

48. Schumacker, P.T.; Rowland, J.; Saltz, S.; Nelson, D.P.; Wood, L.D. Effects of hyperthermia and hypothermia on oxygen extraction by tissues during hypovolemia. J. Appl. Physiol. 1987, 63, 1246-1252. doi: 10.1152/jappl.1987.63.3.1246.

49. Rokyta, R. Jr.; Matejovic, M.; Krouzecky, A.; Opatrny, K. Jr.; Ruzicka, J.; Novak, I. Effects of continuous venovenous haemofiltration-induced cooling on global haemodynamics, splanchnic oxygen and energy balance in critically ill patients. Nephrol. Dial. Transplant. 2004, 19, 623-630. doi: 10.1093/ndt/gfg615

50. Manthous, C.A.; Hall, J.B.; Olson, D.; Singh, M.; Chatila, W.; Pohlman, A.; Kushner, R.; Schmidt, G.A.; Wood L.D. Effect of cooling on oxygen consumption in febrile critically ill patients. Am. J. Respir. Crit. Care. Med. 1995, 151, 10-14. doi: 10.1164/ajrccm.151.1.7812538. 
51. Götberg, M.; van der Pals, J.; Olivecrona, G.K.; Götberg, M.; Koul, S.; Erlinge, D. Mild hypothermia reduces acute mortality and improves hemodynamic outcome in a cardiogenic shock pig model. Resuscitation. 2010, 81, 1190-1196. doi: 10.1016/j.resuscitation.2010.04.033.

52. Zobel, C.; Adler, C.; Kranz, A.; Seck, C.; Pfister, R.; Hellmich, M.; Kochanek, M.; Reuter, H. Mild therapeutic hypothermia in cardiogenic shock syndrome. Crit. Care Med. 2012, 40, 1715-1723. doi: 10.1097/CCM.0b013e318246b820.

53. Schortgen, F.; Clabault, K.; Katsahian, S.; Devaquet, J.; Mercat, A.; Deye, N.; Dellamonica, J.; Bouadma, L.; Cook, F.; Beji, O.; et al. Fever control using external cooling in septic shock: a randomized controlled trial. Am. J. Respir. Crit. Care. Med. 2012, 185, 1088-1095. doi: 10.1164/rccm.201110-1820OC. 
Table 1. Demographic, virological, laboratory, severity scoring, and clinical data for each patient. HVHF, high volume hemofiltration; RT-qPCR ANDV, Andes Hantavirus specific reversetranscription polymerase chain reaction; IgM ANDV, Andes Hantavirus specific immunoglobulin M; n/a, non-available; +, positive test; APACHE II, acute physiology and chronic health evaluation II; SOFA, sequential organ failure assessment; ICU, intensive care unit; LOS, length of stay; IMV, invasive mechanical ventilation. *Patient 5 was transferred from and back to another hospital. *The negative time interval refers to intubation being prior to admission to our center. ${ }^{\$}$ Hospital-LOS is the shortest because once extubated, this patient was transferred back to the referring center.

\begin{tabular}{lcccccc}
\hline \multirow{2}{*}{ Characteristic } & \multicolumn{2}{c}{ HVHF } & \multicolumn{3}{c}{ HVHF } \\
& nonresponders & \multicolumn{3}{c}{ responders } \\
\cline { 2 - 6 } & $\mathbf{1}$ & $\mathbf{2}$ & $\mathbf{3}$ & $\mathbf{4}$ & $\mathbf{5}^{*}$ \\
\hline Age, years & 15 & 15 & 17 & 22 & 29 \\
Weight, Kg & 64 & 63 & 67 & 72 & 81 \\
RT-qPCR ANDV & + & + & + & + & + \\
IgM ANDV & $\mathrm{n} / \mathrm{a}$ & + & + & $\mathrm{n} / \mathrm{a}$ & + \\
Viremia, copies/mL blood & $2.4 \times 10^{5}$ & $2.7 \times 10^{4}$ & $8.2 \times 10^{3}$ & $4.1 \times 10^{4}$ & undetectable \\
Prodromal period, days & 5 & 4 & 5 & 7 & 6 \\
Lowest platelet count, K/mm ${ }^{3}$ & 37 & 27 & 42 & 49 & 85 \\
Highest hematocrit, \% & 48.9 & 48.4 & 55.8 & 44.3 & 47 \\
Highest blood lactate, mMol/L & 7.37 & 3.44 & 15.16 & 3.12 & 5.39 \\
APACHE II score, points & 10 & 17 & 14 & 8 & 14 \\
Admission SOFA score, points & 4 & 11 & 10 & 9 & 11 \\
Highest SOFA score, points & 12 & 14 & 10 & 10 & 12 \\
Admission to intubation interval, & 17 & 2 & 1 & 1 & $-24^{*}$ \\
hours & & & & & \\
Admission to immune plasma & 15 & 2 & 4 & 1.5 & 1 \\
administration, hours & 14 & 18 & 6 & 3 & 4 \\
ICU-LOS, days & 9 & 10 & 4 & 2 & 4 \\
Time on IMV, days & 20 & 87 & 13 & 6 & $4^{\$}$ \\
Hospital-LOS, days & & & & & \\
\hline
\end{tabular}


Table 2. Hemodynamic and respiratory variables for each patient. HVHF, high volume hemofiltration; ITBVi, intrathoracic blood volume index; EVLWi, extravascular lung water index; PVPI, pulmonary vascular permeability index; $\mathrm{PaO}_{2} / \mathrm{FiO}_{2}$, arterial oxygen partial pressure to fraction of inspired oxygen ratio; LIS, lung injury score [1-4 points]. LIS greater than 2.5 points has been considered diagnostic for the acute respiratory distress syndrome.

\begin{tabular}{|c|c|c|c|c|c|}
\hline \multirow[t]{2}{*}{ Characteristic } & \multicolumn{3}{|c|}{$\begin{array}{c}\text { HVHF } \\
\text { nonresponders }\end{array}$} & \multicolumn{2}{|c|}{$\begin{array}{c}\text { HVHF } \\
\text { responders }\end{array}$} \\
\hline & 1 & 2 & 3 & 4 & 5 \\
\hline \multicolumn{6}{|l|}{ Transpulmonary thermodilution variables } \\
\hline Highest heart rate, beats/min & 148 & 138 & 124 & 111 & 145 \\
\hline Lowest stroke index, $\mathrm{mL} / \mathrm{m}^{2}$ & 13.9 & 11.6 & 15 & 20.1 & 29 \\
\hline Lowest cardiac index, $\mathrm{L} / \mathrm{min} / \mathrm{m}^{2}$ & 1.75 & 1.7 & 1.76 & 1.9 & 2.76 \\
\hline Lowest ITBVi, $\mathrm{mL} / \mathrm{m}^{2}$ & 451 & 447 & 461 & 467 & 644 \\
\hline Highest EVLWi, mL/Kg & 15.9 & 25.3 & 21.3 & 14 & 18.2 \\
\hline Highest PVPI, dimensionless & 6.4 & 8.3 & 7.8 & 5 & 10 \\
\hline \multicolumn{6}{|l|}{ Vasoactive support } \\
\hline Noradrenaline highest dose, $\mu \mathrm{g} / \mathrm{Kg} / \mathrm{min}$ & 0.16 & 0.45 & 0.18 & 0.15 & 0.04 \\
\hline Dobutamine highest dose, $\mu \mathrm{g} / \mathrm{Kg} / \mathrm{min}$ & 1 & 0 & 1 & 0 & 0 \\
\hline Adrenaline highest dose, $\mu \mathrm{g} / \mathrm{Kg} / \mathrm{min}$ & 0 & 0.03 & 0.18 & 0 & 0.2 \\
\hline Milrinone highest dose, $\mu \mathrm{g} / \mathrm{Kg} / \mathrm{min}$ & 0.25 & 0 & 0.5 & 0 & 0 \\
\hline \multicolumn{6}{|l|}{ Respiratory variables } \\
\hline Lowest $\mathrm{PaO}_{2} / \mathrm{FiO}_{2}$, dimensionless & 97 & 125 & 133 & 295 & 166 \\
\hline Highest oxygenation index, dimensionless & 20.6 & 11.6 & 11.7 & 4.6 & 11.4 \\
\hline LIS, points & 3.75 & 2.8 & 2.8 & 2.5 & 2.3 \\
\hline
\end{tabular}


Figure 1. Time-course of hemodynamic variables before and after the onset of HVHF and grouped according to HVHF responsiveness. HVHF-nonresponders required VA-ECMO. Each color represents a single patient: patient 1 , blue; patient 2 , red; patient 3 , black; patient 4 , green; patient 5 , orange. The period prior to the onset of HVHF is marked with continuous lines. The period of HVHF is marked with dashed lines; standard HVHF is marked with short-dashed lines and targeted HVHF marked with long-dashed lines. Patient 3 has both of them, and patient 5 has only a targeted HVHF period. The abscissa is time and the numbers on it indicate correlative measurements rather than strict units of time. HVHF, high volume hemofiltration; VA-ECMO, veno-arterial extracorporeal membrane oxygenation; ITBVi, intrathoracic blood volume index.
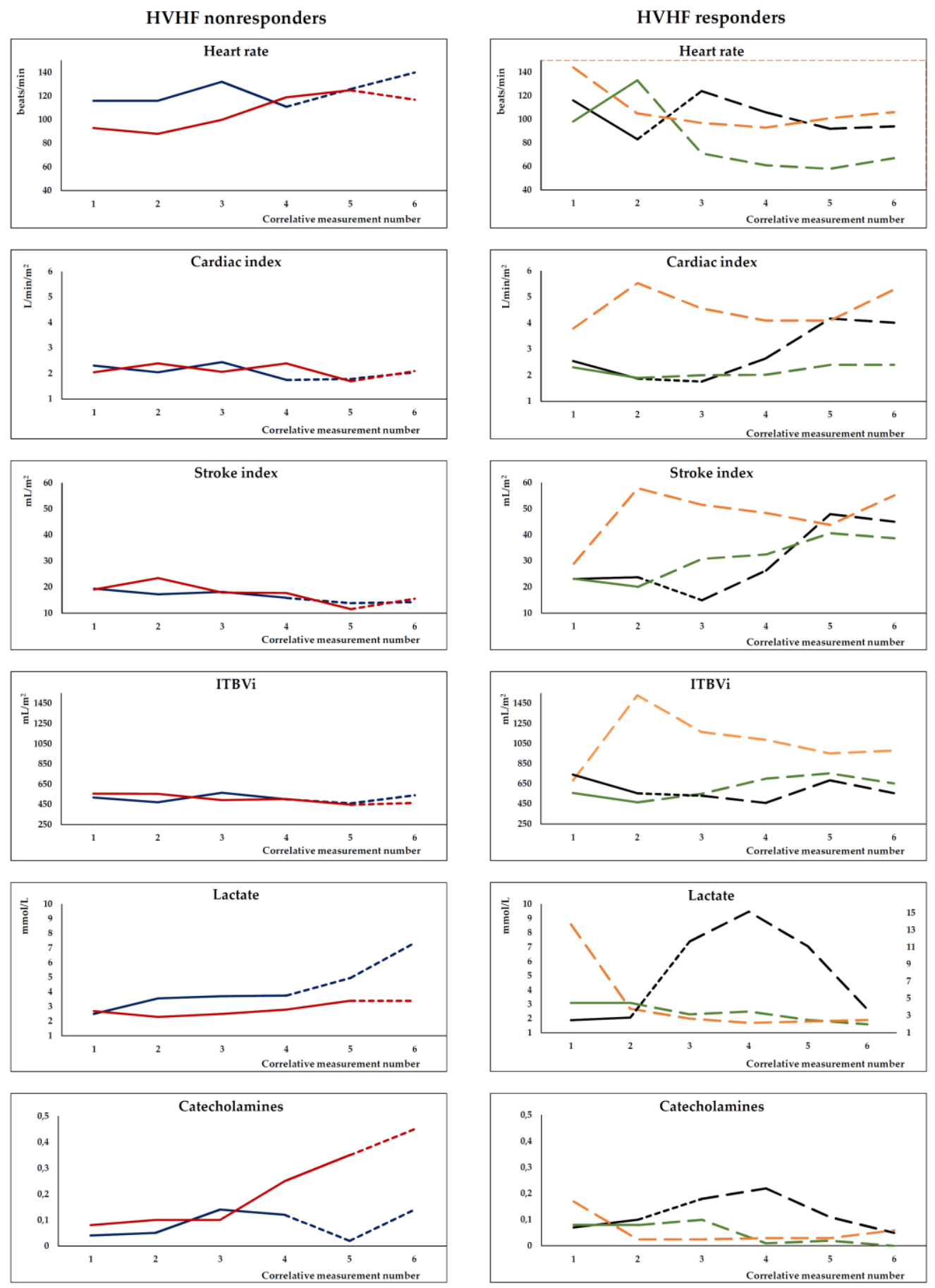
Figure 2. Time-course of respiratory variables before and after the onset of HVHF and grouped according to HVHF responsiveness. HVHF-nonresponders required VA-ECMO. Each color represents a single patient: patient 1 , blue; patient 2 , red; patient 3 , black; patient 4 , green; patient 5 , orange. The period prior to the onset of HVHF is marked with continuous lines. The period of HVHF is marked with dashed lines; standard HVHF is marked with short-dashed lines and targeted HVHF marked with long-dashed lines. Patient 3 has both of them, and patient 5 has only a targeted HVHF period. The abscissa is time and the numbers on it indicate correlative measurements rather than strict units of time. HVHF, high volume hemofiltration; VA-ECMO, veno-arterial extracorporeal membrane oxygenation; $\mathrm{PaO}_{2} / \mathrm{FiO}_{2}$ ratio, arterial oxygen partial pressure to fraction of inspired oxygen ratio; PEEP, positive end-expiratory pressure; OI, oxygenation index; EVLWi, extravascular lung water index; PVPI, permeability vascular pulmonary index.
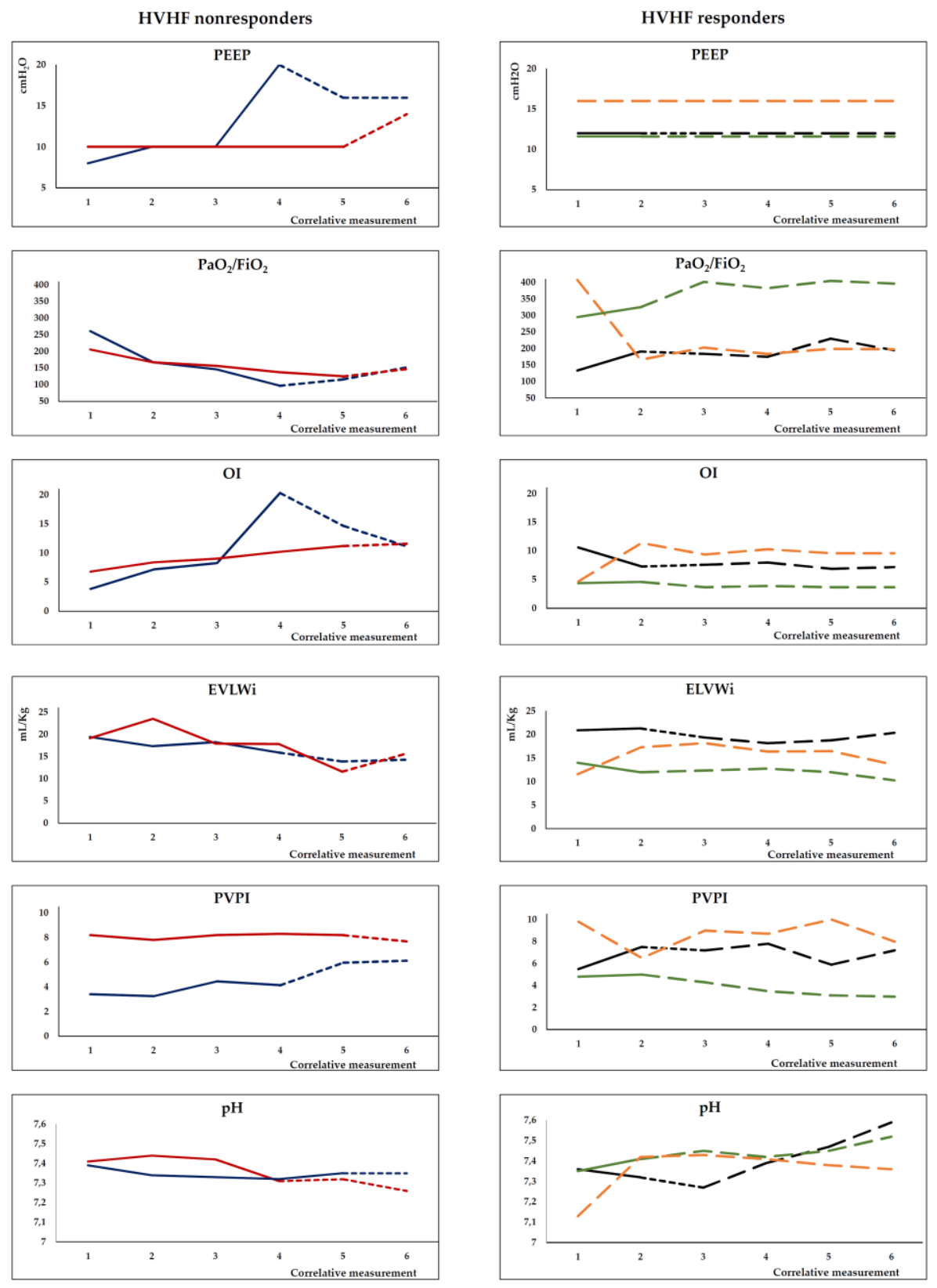
Table 3. Hemofiltration variables and external addition of intravenous hyperoncotic albumin, bicarbonate and calcium during HVHF. HVHF, high volume hemofiltration; $\mathrm{Qb}$, circuit blood flow; Qr, replacement flow; 3 S, patient 3 during standard HVHF; 3 T, patient 3 during targeted HVHF. *Patient 5 was transferred from another hospital. ${ }^{*}$ This patient was intubated 24 hours prior to admission to our center; HVHF started within 3 hours of admission to our center.

\begin{tabular}{lccccccc}
\hline \multirow{2}{*}{ Characteristic } & \multicolumn{3}{c}{$\begin{array}{c}\text { HVHF } \\
\text { nonresponders }\end{array}$} & \multicolumn{3}{c}{$\begin{array}{c}\text { HVHF } \\
\text { responders }\end{array}$} \\
\cline { 2 - 8 } & $\mathbf{1}$ & $\mathbf{2}$ & $\mathbf{3 ~ S}$ & $\mathbf{3 ~ T}$ & $\mathbf{4}$ & $\mathbf{5}^{*}$ \\
\hline Intubation to HVHF onset interval, hours & 30 & 15 & 11 & 20 & 8 & $27 / 3^{*}$ \\
HVHF run, hours & 14 & 15 & 9 & 6 & 9 & 9 \\
Qb, mL/min & 230 & 200 & 200 & 200 & 270 & 250 \\
Qr, $\mathrm{mL} / \mathrm{Kg} / \mathrm{h}$ & 78 & 71 & 60 & 60 & 56 & 74 \\
Net ultrafiltered volume, mL & 0 & 0 & 0 & 2490 & 3690 & 4800 \\
20\% albumin addition, g & 10 & 40 & 0 & 80 & 40 & 80 \\
Bicarbonate addition, mmol & 266 & 67 & 500 & 583 & 166 & 500 \\
Calcium addition, mmol & 3.25 & 0 & 0 & 3.25 & 3.25 & 3.25 \\
\hline
\end{tabular}

Table 4. Changes in laboratory and transpulmonary thermodilution variables induced by HVHF. HVHF, high volume hemofiltration; T0, evaluation prior to HVHF; T-S, evaluation after the standard HVHF run or at the time of connection to VA-ECMO; T-T, evaluation after the targeted HVHF run; HVHF, high volume hemofiltration; VA-ECMO, veno-arterial extracorporeal membrane oxygenation; n/a, non-available; ITBVi, intrathoracic blood volume index; SVV, stroke volume variation; EVLWi, extravascular lung water index.

\begin{tabular}{|c|c|c|c|c|c|c|c|c|c|c|c|}
\hline \multirow{3}{*}{ Characteristic } & \multicolumn{5}{|c|}{$\begin{array}{c}\text { HVHF } \\
\text { nonresponders }\end{array}$} & \multicolumn{6}{|c|}{$\begin{array}{c}\text { HVHF } \\
\text { responders }\end{array}$} \\
\hline & \multicolumn{2}{|c|}{1} & 2 & \multicolumn{2}{|r|}{3} & \multicolumn{4}{|c|}{4} & \multicolumn{2}{|c|}{5} \\
\hline & T0 & T-S & T0 & T-S & T0 & T-S & T-T & T0 & T-T & T0 & T-T \\
\hline \multicolumn{12}{|l|}{ Laboratory variables } \\
\hline $\mathrm{pH}$ & 7.31 & 7.26 & 7.35 & 7.38 & 7.44 & 7.27 & 7.59 & 7.35 & 7.45 & 7.13 & 7.36 \\
\hline Bicarbonate, mMol/L & 23 & 18.5 & 22.2 & 23.3 & 25 & 17.7 & 26.4 & 22.3 & 26.8 & 13.7 & 23.1 \\
\hline Lactate, $\mathrm{mMol} / \mathrm{L}$ & 3.76 & 7.37 & 3.44 & 3.11 & 2.05 & 11.7 & 3.75 & 3.12 & 2.46 & 5.39 & 1.84 \\
\hline Ionzed calcium, mg/dL & 4.8 & 4.8 & 4.6 & 5.0 & 3.9 & 4.3 & 4.8 & 4.6 & 4.4 & 4.0 & 5.2 \\
\hline Hematocrit, \% & 48 & 48.9 & 44.1 & 47.2 & 55.8 & 52.1 & 39.7 & 44.3 & 36.4 & 47 & 34 \\
\hline $\begin{array}{l}\text { Serum albumin, } \\
\mathrm{mg} / \mathrm{dL}\end{array}$ & 2.8 & 2.5 & 2.9 & 2.0 & 3.8 & 2.7 & 4.6 & 2.6 & 2.3 & 2.0 & 3.7 \\
\hline \multicolumn{12}{|c|}{ Transpulmonary thermodilution variables } \\
\hline Temperature, ${ }^{\circ} \mathrm{C}$ & 39.9 & 36.9 & 38.6 & 36.6 & 36.7 & $\mathrm{n} / \mathrm{a}$ & $\mathrm{n} / \mathrm{a}$ & 37.4 & 35.5 & 37.1 & 36.3 \\
\hline Heart rate, beats/min & 132 & 140 & 125 & 102 & 98 & 111 & 99 & 96 & 61 & 145 & 113 \\
\hline Stroke index, mL/m² & 18.2 & 14.3 & 11.6 & 9.6 & 36.4 & 27.8 & 50.3 & 22.5 & 32.7 & 29 & 54.3 \\
\hline ITBVi, mL/m² & 565 & 451 & 447 & 275 & 742 & 629 & 686 & 467 & 702 & 686 & 1017 \\
\hline SVV, \% & 18 & 23 & 6 & 10 & 19 & 12 & 9 & 10 & 8 & 7 & 5 \\
\hline EVLWI, mL/Kg & 12.4 & 14.7 & 20.3 & 8.8 & 20.9 & 18.8 & 16.5 & 12 & 12.8 & 11.6 & 13.1 \\
\hline
\end{tabular}

